\title{
Considerações sobre o code-switching em O Senhor dos Anéis: o caso do quenya e do sindarin
}

\author{
Vinicius Borges de Almeida* \\ Isabella Mozzillo**
}

\begin{abstract}
Eu acredito que seja um "fato" primordial sobre minha obra, o de que ela é inteiramente consistente e fundamentalmente linguística em inspiração. [...] A invenção de idiomas é a base. As "histórias" foram antes criadas para fornecerem um mundo para os idiomas do que o contrário.J.R.R. Tolkien em Cartas de J.R.R. Tolkien (1981)
\end{abstract}

\begin{abstract}
Resumo: Este artigo pretende investigar o fenômeno da alternância de código (ou codeswitching) em O Senhor dos Anéis, uma trilogia escrita por J. R. R. Tolkien. Escritor e filólogo, ele foi o responsável pela criação de muitas línguas, sendo estas atribuídas às personagens conforme seus povos e origens. O objetivo desta investigação é descrever a alternância de código na trilogia a fim de encontrar possíveis motivações de ocorrência e de situar seu papel dentro da narrativa.
\end{abstract}

Palavras-chave: Línguas em contato. Línguas artificiais. Code-switching.

\begin{abstract}
This article intends to investigate the code-switching in The Lord of the Rings, a trilogy written by J.R.R. Tolkien. Writer and philologist, he was the responsible for the creation of many languages, which are attributed to the characters according to their people and origins. The aim of this investigation is to describe the code-switching into this trilogy, trying to find some motivations and to identify its role inside the story.
\end{abstract}

Key words: Language contact. Artificial languages. Code-switching.

Résumé: Cet article se propose à examiner l'alternance codique (ou code-switching) dans Le Seigneur des Anneaux, une trilogie écrite par J.R.R. Tolkien. Écrivain et philologue, il a été le responsable dela création de plusieurs langues, qui sont attribuées aux personnages selon leurs peuples et origines. L'objectif de cette investigation est de décrire l'alternance codique dans la trilogie afin de retrouver quelques motivations et de situer son rôle dans le récit.

\footnotetext{
* Mestrando em Letras, área de Aquisição, Variação e Ensino pela Universidade Federal de Pelotas. http://orcid.org/oooo-0002-4436-4880

${ }^{* *}$ Professora titular no curso de Licenciatura em Letras - Português e Francês e do Programa de PósGraduação em Letras da Universidade Federal de Pelotas. http://orcid.org/oooo-ooo1-8445-9174
}

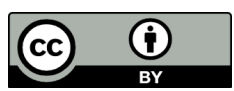


Mots-clés: Langues en contact. Langues artificielles. Code-switching.

\section{Introdução}

O presente trabalho propõe-se a investigar e a descrever aspectos do codeswitching em O Senhor dos Anéis, escrito por J. R. R. Tolkien. Escolheu-se trabalhar com essa trilogia porque Tolkien, escritor e filólogo, preocupou-se não somente em produzir o enredo de sua narrativa, mas também em criar línguas e atribuí-las a seus personagens conforme suas raças e origens. Portanto, pode ser considerado um universo narrativo multilíngue.

Ora, se há duas ou mais línguas nesse espaço, é possível crer que alguns fenômenos do contato entre elas já descritos para línguas naturais também acontecerão em contextos onde há idiomas criados. É o caso do code-switching.

Assim, o artigo versará, primeiramente, um panorama histórico sobre línguas artificiais; em seguida, comentará brevemente a respeito de J. R. R. Tolkien e O Senhor dos Anéis; e, finalmente, esclarecerá o conceito de code-switching, a partir do qual analisará e discutirá trechos retirados da trilogia.

\section{Línguas artificiais: um panorama histórico}

Não é de hoje que a criação de línguas é um objeto sobre o qual tanto linguistas quanto leigos se debruçam. As primeiras evidências de um projeto para a (re)construção de uma lingua mater ou uma língua auxiliar universal datam dos séculos XVII e XVIII, época em que o latim ainda era utilizado como língua dos eruditos, porém sendo gradativamente substituído pelas línguas nacionais. Essa “aventura” (RÓNAI, 1970; STÖRIG, 1990) seria uma tentativa de reaproximar os povos a uma língua em que todos pudessem se comunicar - um plano contra a "confusão de línguas" imposta por Deus no relato bíblico da Torre de Babel em Gênesis 11. Através desse objetivo, parece haver uma 
boa justificativa para a emergência de uma língua artificial a fim de estabelecer uma comunicação universal.

Mais tarde, no século XIX, houve a retomada do princípio da characteristica universalis proposto pelo matemático Gottfried Leibniz (1646-1716). Conforme suas conclusões, todas as concepções complexas do cérebro podem ser decompostas em elementos simples, ou seja, o processo de pensamento nada mais é do que um processo de cálculo. Sobre esse princípio, Störig (1990) relata que

seria possível construir um vocabulário sistematicamente ordenado, baseado em um inventário de todas as 'ideias simples' [...]. Para poder manejar tal vocabulário seria necessária então uma gramática universal, que - diferente das gramáticas de todas as línguas vivas - precisa ser de uma regularidade absoluta, sem exceções e da máxima simplicidade: diversas declinações e conjugações são supérfluas. (STÖRIG, 1990, p. 248)

Embora alguns projetos de línguas ${ }^{1}$ tenham surgido - como o solresol e o volapük - elas não obtiveram êxito: a primeira, baseada nas sete notas musicais, era um sistema demasiado distante de qualquer língua natural; já a segunda possuía muitos elementos gramaticais considerados complexos (sistema de declinações, vasto paradigma verbal etc.).

Uma língua artificial, entretanto, merece destaque. Sob o pseudônimo de Dr. Esperanto ("o esperançoso"), o polonês Ludwig Zamenhof cunhou o esperanto e publicou materiais sobre e nessa língua, a qual se popularizou por sua gramática simples e seu vocabulário acessível. Há poemas nesse idioma; é uma língua falável e pode ser cantada, pois apresenta ricas possibilidades expressivas. E foi assim durante mais de um século, uma vez que ela também se alicerçou noutro ideal de Zamenhof: ele a considerava uma maneira de promulgar a paz mundial e a fraternidade entre as pessoas; a ligação entre o esperanto e a doutrina espírita (e alguns fiéis da igreja católica), portanto, fez com que ele tivesse uma sobrevida maior em relação aos outros exemplos mencionados. 
Não se pode deixar de relatar a observação feita por Störig (1990, p. 253), segundo a qual “os projetos elaborados até o presente são, em sua grande maioria, eurocêntricos: partem das línguas da Europa e [...] se comportam como se o restante da humanidade, majoritário, devesse aceitar esta língua dos europeus." Nesses moldes, fica evidente que os ideais de criação (e de imposição) de uma língua auxiliar seriam mais um projeto de supremacia do Ocidente do que realmente um passo em direção à comunicação universal.

Mas esses não são os únicos motivos para a criação de línguas. Outro grupo expressivo dentro das línguas artificiais são as línguas artísticas, cujo objetivo principal não é a comunicação (pelo menos em se tratando de contextos reais). O escritor George R. R. Martin criou as línguas valirianas para a obra literária “As Crônicas de Gelo e Fogo”, tendo destaque o alto valiriano. Há documentado todo seu sistema fonológico e de escrita, bem como uma porção de verbos, adjetivos e substantivos.

O “artista”, ou seja, o responsável pela criação de uma língua, pode rebuscá-la o quanto quiser, tendo sido (ou não) inspirado por outra(s) natural(is). A intenção aqui é usá-la em prosas e poesias cuidadosamente preparadas em vez de conversas casuais por isso, um método de estudo a partir de diálogos e simulações de situações relacionadas à vida diária seria um tanto sem sentido. É nessa categoria que também se incluem J. R. R. Tolkien e as línguas por ele criadas, em especial o quenya e o sindarin, que serão tratados posteriormente.

\section{O Senhor dos Anéis}

John Ronald Reuel Tolkien (1892-1973) nasceu na África do Sul, mas desenvolveu boa parte de sua carreira acadêmica e artística no Reino Unido. Professor emérito de filologia da Universidade de Oxford com longa lista de publicações na academia, também escreveu obras consagradas de ficção, tais como O Senhor dos Anéis, O Hobbit e O Silmarillion. Há ainda muitos outros contos e poemas que, porém, permanecem pouco conhecidos. 
Segundo Greggersen (2013, p. 14), Tolkien desenvolveu hábitos peculiares desde tenra idade, sendo um deles "o de observar e atentar para os detalhes das paisagens e, particularmente, da topografia dos lugares que conhecia.” Além disso, a pesquisadora também destaca que "outra paixão que lhe foi despertada desde cedo, particularmente por sua mãe, foi a diversidade de idiomas, especialmente os germânicos, o galês e o finlandês (...)” (GREGGERSEN, 2013, p. 15). Esses dois aspectos do professor-artista levam a crer que o processo de criação de seus universos literários é rico em descrições minuciosas do espaço (vegetação, topografia, edificações) e das personagens (trajes, aspectos físicos e identitários, tais como singularidades de cada povo, em especial as questões relacionadas às línguas).

A obra ficcional mais longa e desenvolvida de toda a carreira de J. R. R. Tolkien foi O Senhor dos Anéis (em inglês, The Lord of The Rings). A primeira publicação no Reino Unido foi extremamente dispendiosa, já que a maior parte dos custos deveu-se ao alto preço do papel no pós-guerra. Contudo, a fim de conseguir manter um valor acessível na primeira edição, o livro foi dividido em três volumes: The Fellowship of the Ring, publicado em 1954, The Two Towers, publicado alguns meses depois, The Return of the King e mais seis apêndices, publicado em 1955.

White (2016, p. 218) relata que, logo em seguida das publicações, houve expressiva mobilização da crítica literária. Ele comenta a opinião do crítico britânico Howard Spring, que considerou o primeiro volume “(...) uma obra de arte. Possui invenção, fantasia e imaginação. É uma parábola profunda da luta sem fim do homem contra o mal.” Entretanto, havia outros que não economizaram em depreciar ferrenhamente o trabalho de Tolkien. White (2016, p. 219) também apresenta outra perspectiva, a do norte-americano Edmund Wilson, que julgou a obra "uma bobagem (...) um lixo juvenil" e que ela "somente teria apelo ao gosto literário britânico."

Contrariando as expectativas de Wilson, a trilogia foi consagrada em todo o mundo, tendo sido traduzida para muitas línguas e adaptada ao cinema pelo diretor e cineasta Peter Jackson.

No Brasil, as primeiras traduções para o português foram publicadas entre 1974 e 1979 pela extinta editora Artenova do Rio de Janeiro. Cada volume da série foi dividido 
em dois tomos, sendo estes, por sua vez, vendidos separadamente. Eram intitulados "Terra Mágica", "O Povo do Anel" (que formavam A Sociedade do Anel), "As Duas Torres", "A Volta do Anel" (que formavam As Duas Torres), "O Cerco de Gondor" e "O Retorno do Rei" (que fechavam a série formando o terceiro e último volume original, O Retorno do Rei). A última edição em língua portuguesa foi realizada pela editora brasileira Martins Fontes em 1991 e publicada em 1994. Nessa nova edição, a Martins Fontes uniu novamente os tomos em seus respectivos volumes, como publicado originalmente no Reino Unido, sob os mesmos títulos, devidamente traduzidos.

Daqui para frente, alguns aspectos do code-switching serão discutidos para posterior análise de trechos dos três volumes de O Senhor dos Anéis.

\section{$O$ code-switching}

Segundo Grosjean (1994, p. 168), entende-se por code-switching "uma mudança completa de língua por meio de uma palavra, uma frase ou uma sentença”, sendo descrito como um fenômeno inerente à conversação entre bilíngues que dominam o mesmo par de línguas. No momento em que os interlocutores entram em contato, eles podem optar por variantes linguísticas e estilísticas conforme a situação, geralmente para se obter ganhos comunicativos. Nesse sentido, Mozzillo (2009) considera que "lançar mão de elementos de uma e outra língua no mesmo ato comunicativo constitui uma estratégia comunicativa que é sinal de uma competência pragmática compartilhada por bilíngues ao transmitirem uma informação.” A autora ainda relata que ouvir e produzir enunciados noutra língua, mudando aspectos formais da conversação, levam os bilíngues a inferir que algo a mais está sendo comunicado.

Em geral, a transição entre as línguas é feita de maneira tácita e fluida, isto é, sem a necessidade de que haja uma transição consciente. Os interlocutores, por vezes, nem se dão conta de que estão alternando, como nos casos apresentados por Grosjean (1994, p. 168) entre francês-inglês e entre inglês-espanhol: 
"Va chercher Marc and bribe him avec un chocolat chaud with cream on top."

(Vá buscar o Marc e suborne-o com um chocolate quente com creme).

"So you todavía haven't decided lo que vas a hacer next week."

(Então, você ainda não decidiu o que vai fazer na semana que vem).

No intuito de classificar a alternância de código realizada pelos interlocutores, Dabène e Moore (1995) propuseram três tipos conforme ela ocorre: o intrassentencial, o intersentencial e o entre enunciados.

O primeiro deles acontece quando, numa mesma sentença, há alternância entre os sistemas através de inserções, tanto sob a forma unitária (apenas um elemento da frase é afetado), quanto sob a forma segmental (segmentos de uma língua se alternam com partes da outra dentro da mesma frase, como nos exemplos mencionados acima).

Já o segundo se dá no momento em que as línguas se alternam de uma sentença a outra dentro do mesmo tópico de conversação, porém não no mesmo turno de fala. Tal tipo de alternância é percebido em um dos trechos descritos por Mozzillo de Moura (1997, p. 13):

[...] (em espanhol)

A: mi teléfono hace ruidos bizarros sabés, ¿no?

B: qué asco

A: eh sí, es una cosa asquerosa

B: tá, eu te contei que amanhã eu vou lá na M.L. ter aulas com ela?

A: não, aula de quê?

[...] (em português)

Por fim, o terceiro tipo é verificado quando a alternância para a outra língua manifesta-se após um período bastante longo de uso da primeira. Tal fenômeno aparece em um mesmo diálogo, quando a primeira frase proferida na língua de base da interação encontra-se relativamente distante da primeira frase pronunciada no sistema alternativo (língua convidada). 
Outro ponto importante a ser ressaltado é que o code-switching, independentemente do tipo, tem sempre um fator motivador, que pode, por sua vez, ser identificado e analisado, mesmo que os próprios interlocutores não o façam conscientemente. Dentre os fatores já descritos, Mozzillo de Moura (1997) ressalta motivações linguísticas, sociolinguísticas, estilísticas, cognitivas, emocionais, ambientais, de disponibilidade na memória, de solidariedade com o interlocutor, de demonstração de poder, de lealdade a uma cultura, de manutenção de código, de mudança de tópico, de realização de digressões, de comicidade e de preferência pessoal por um dos idiomas.

Essa lista de motivações, até então atribuída a situações de línguas naturais, servirá de base para analisar o code-switching em que há línguas artificiais envolvidas, a fim de verificar se tais razões também ocorrem nessas interações ou se há ainda outros fatores relevantes para se alternar de código.

\section{Metodologia}

A partir da leitura de toda a série, foi possível separar trechos de falas das personagens em que havia alternância de código. Eles foram selecionados para formar um corpus contendo vinhetas de tais interações. A partir do levantamento, foram consideradas alternâncias para o quenya e para o sindarin, duas das muitas línguas artificiais do universo de Tolkien. O critério para escolhê-las está no fato de elas serem as duas línguas tolkenianas mais completas, com materiais escritos nelas e sobre elas. Há, inclusive, cursos através dos quais é possível aprendê-las.

A língua em que se passa a narrativa é o westron² (ou "língua geral"). No decorrer da Terceira Era da Terra-média (época em que se passa a narrativa no universo fictício de "O Senhor dos Anéis"), o westron tornara-se a língua nativa de quase todos os povos falantes ou era usado como segunda língua de comunicação por aqueles que eram

\footnotetext{
${ }^{2} \mathrm{O}$ westron é uma "língua neutra", ou seja, é o nome dado por Tolkien para o idioma no qual os livros foram escritos.
}

Revista Investigações, Recife, v. 33, n. 2, p. 1 - 16, 2020 ISSN Digital 2175-294X 
nativos de outras línguas. Os trechos utilizados para a análise neste trabalho contemplarão as seguintes raças: elfos, homens e hobbits.

O objetivo desta pesquisa é, portanto, descrever aspectos do code-switching que acontece nas interações entre as personagens que dominam o westron, o quenya e o sindarin (pertencentes ou não ao mesmo povo); qual o tipo de code-switching (intrassentencial, intersentecial ou entre enunciados); e quais seriam prováveis razões ou motivações pelas quais ele ocorre segundo o modelo descrito por Mozzillo de Moura (1997). Embora seja interessante avaliar aspectos gramaticais e estruturais das línguas criadas por Tolkien, este trabalho pretende apenas situar o papel delas dentro da narrativa.

\section{Discussão}

Como colocado na epígrafe deste trabalho, Tolkien ressalta que sua obra é fruto de uma inspiração primordialmente linguística. Para ele, fornecer um pano de fundo histórico para as línguas de sua criação era uma condição sine qua non.

Essa ideia traz consigo duas constatações importantes: primeiramente, o autor teve o esforço e o cuidado para criar as línguas e depois lhes conceder um pano de fundo, e não o contrário. Além disso, vê-se que "os mitos associados certamente enriquecem (...) e nos ajudam a compreender que tipo de 'sabor' linguístico Tolkien almejava (...)” (FAUSKANGER, 2011). Por outro lado, ao fazer isso, o escritor não somente compôs os mitos, mas também sustentou seus idiomas criados ao fornecer-lhes o essencial: falantes.

Para que a análise seja feita, é preciso traçar minimamente o repertório de línguas envolvidas nos diálogos entre as personagens. Logo abaixo, está descrito o repertório de línguas de, respectivamente, elfos, homens e hobbits conforme o apêndice F de "O Retorno do Rei” (TOLKIEN, 200o, p. 419-422):

O alto-élfico (ou quenya) e o élfico-cinzento (ou sindarin) para os elfos. O primeiro não era mais uma língua nativa, mas tornara-se um "latim élfico", restrito a cerimônias tradicionais e canções; o segundo, entretanto, era adotado no uso diário e, dessa forma, tornou-se a língua de todos os elfos e senhores élficos que aparecem na 
história. Também eram capazes de utilizar facilmente o westron para se comunicarem com outros povos.

O westron (ou "língua geral") era a língua falada pelos homens. Apenas parte deles, os dúnedain, conhecia também o sindarin e desses, alguns ainda haviam tido contato com o quenya por suas relações com os elfos no passado. Outros ainda falavam as línguas do próprio reino, tais como os habitantes de Rohan.

Os hobbits haviam adotado a "língua geral" desde muito antes da época de "O Senhor dos Anéis”. O protagonista Frodo e seu tio Bilbo eram exceções, pois também haviam aprendido incipientemente o quenya e o sindarin através do contato com elfos.

Uma vez conhecendo esse padrão, passa-se agora para a análise dos trechos e de quatro possíveis motivações (solidariedade com o interlocutor; lealdade a uma cultura; situações de perigo ou ameaça; e rituais e cerimônias) para a ocorrência de codeswitching:

1. Solidariedade com o interlocutor - "pode haver alternância ou mesmo manutenção do código linguístico com o fim de exprimir sentimentos de companheirismo ou compreensão.” (MOZZILLO DE MOURA, 1997, p. 9).

No trecho ${ }^{3}$ abaixo, Frodo (um hobbit), ao despedir-se de Gildor (um senhor elfo), alterna do westron para o quenya, proferindo uma sentença de despedida comum nessa língua, traduzindo-a logo em seguida:

"Agradeço-lhe muito, Gildor Inglorion - disse Frodo, fazendo uma reverência. - Elen síla lúmenn' omentielvo, uma estrela brilha sobre a hora do nosso encontro - acrescentou ele, na língua dos Altos-elfos.

- Tenham cuidado, amigos - gritou Gildor, rindo. Não digam segredos! Aqui está um estudioso da Língua Antiga. Bilbo foi um bom mestre. Salve, amigodos-elfos! Disse Gildor, fazendo uma reverência a Frodo.”

\footnotetext{
3 Todos os trechos apresentados no trabalho foram retirados de "O Senhor dos Anéis" (TOLKIEN, 200o), respeitando a pontuação e os grifos do original.
} 
Ao alternar para o quenya, o hobbit demonstra uma relação de afeto com o elfo, aproximando a relação entre eles. A frase inserida no discurso também fez gerar a lembrança de Bilbo, sendo ele, por sua vez, predicado como "um bom mestre" ao passar seus conhecimentos sobre a língua a Frodo. Além disso, suscitou um comportamento de cautela em Gildor que, por sua vez, precisou alertar seus companheiros elfos dos “segredos”, já que Frodo poderia compreendê-los.

2. Lealdade a uma cultura - "Em determinados casos, o emprego de uma determinada língua se impõe como o único possível pela necessidade de expressão plena de traços culturais.” (MOZZILLO DE MOURA, 1997, p. 11).

Em muitos trechos dos livros, houve a inserção de termos enquanto se usava o westron pela especificidade do referente. Afinal, era mais fácil alternar o código do que explicar todas as vezes em que se queria mencioná-los. Isso aconteceu com os termos lembas (nome em quenya para uma espécie de bolo élfico preparado para viagens), miruvor (nome em quenya para o licor de Imladris), athelas (nome em quenya para uma espécie de folhas com propriedades medicinais), simbelmynë (nome em sindarin para uma flor branca que crescia próxima a túmulos) e palantír (nome em quenya para designar uma pedra capaz de mostrar o futuro). É preciso ressaltar que, mesmo se tratando de nomes élficos, personagens de outras raças também os falavam e compreendiam-nos.

Abaixo, estão alguns trechos em que esses termos aparecem e, em seguida, a Tabela $1^{4}$ apresenta a ocorrência de cada um de acordo com os volumes da trilogia:

"Fugimos sem levar quase nada, a não ser alguns pacotes a mais de lembas, e deixamos tudo para trás.”

“Apenas um gole para cada um de nós. É muito precioso. É miruvor, o licor de Imladris."

\footnotetext{
4 Levantamento realizado a partir da leitura dos três volumes de “O Senhor dos Anéis” (TOLKIEN, 200o). Os dados são de responsabilidade dos pesquisadores.
} 
"Estão secas e perderam um pouco o seu poder de cura - disse Aragorn -, mas ainda tenho aqui algumas folhas de athelas que colhi no Topo do Vento."

"Para cá, até o mundo se acabar, nunca virão as flores de simbelmynë.”

“Os palantíri vieram de além do Ponente, de Eldamar”.

Tabela 1. Ocorrência dos termos listados de acordo com os volumes

\begin{tabular}{llllll} 
& lembas & athelas & Miruvor & simbelmynë & palantír \\
\hline Volume 1 & 1 & 2 & 3 & 0 & 0 \\
Volume 2 & 9 & 0 & 0 & 1 & 3 \\
Volume 3 & 3 & 3 & 0 & 1 & 2 \\
\hline
\end{tabular}

Fonte: Tolkien (200o)

3. Situações de perigo ou de ameaça - nessas situações, a alternância de código acontecia ou para pedir ajuda a divindades durante situações de conflito ou para incitar os interlocutores à batalha.

No trecho abaixo, Frodo clama por socorro à deusa Varda (Elbereth, em sindarin) ao recitar o primeiro verso do poema A Elbereth Gilthoniel.

“- O Elbereth! Gilthoniel! - gritou alto, ao mesmo tempo em que golpeou os pés do inimigo.”

Já a seguir, temos a conversa entre Frodo e Legolas (um elfo), pouco antes de avistarem o inimigo. O elfo, vendo a ameaça, alterna do westron para o sindarin:

“- O que foi? - perguntou Frodo.

- Yrch! - disse o elfo num sussurro chiado [...]".

4. Rituais e cerimônias - os elfos eram a raça mais habituada a músicas, a danças, a poemas e a cerimônias. Assim, a maioria das composições artísticas era em quenya.

Dois trechos merecem destaque aqui. O primeiro deles, em A Sociedade do Anel, acontece em um diálogo entre Frodo e Galadriel (uma senhora elfa). Após um longo discurso em westron, ela alterna para o quenya e recita uma poesia de despedida: 
"E você, Portador do Anel - disse ela, voltando-se para Frodo. - Dirijo-me a você por último, embora não seja o último em meus pensamentos. Para você, preparei isto:

\author{
“Ai! laurië lantar lassi súrinen, \\ Yéni únótimë ve rámar aldaron! \\ Yéni ve lintë yuldar avánier \\ mi oromardi lisse-miruvóreva \\ Andulë pella, Vardo tellumar \\ nu luini yassen tintilar i elleni \\ ómaryo airetári-lírinen [...].”5
}

Aqui está a primeira das quatro estrofes do poema Namárië: Altariello nainië Lóriendessë (Adeus: O lamento de Galadriel em Lórien), considerado o maior poema de Tolkien em quenya. Seu nome (Namárië) é uma forma reduzida de a na márië, que significa literalmente "estar bem", uma expressão élfica usada para cumprimentar e para se despedir. No livro, ele é apresentado primeiramente todo em quenya, seguido de sua tradução. Por isso, o leitor não tem necessidade de buscar informações externas sobre ele nem de recorrer a um contexto maior para poder decodificá-lo.

Esse é um bom exemplo de code-switching entre enunciados, contrastando o padrão analisado nos outros trechos em que a alternância de código ocorria de maneira majoritariamente intrassentencial.

O segundo trecho inserido nessa classificação ocorre no fim de "O Retorno do Rei” durante a volta dos hobbits após o êxito de sua missão. Homens e elfos estavam reunidos e, assim, houve manifestações em westron, sindarin e quenya, respectivamente:

“Vida longa aos Pequenos! Louvai-os com grande louvor!

Cuio i Pheriain anann! Aglar 'ni Pheriannath!

\footnotetext{
5 "Ai, como ouro caem as folhas ao vento/ Longos anos inumeráveis como as asas das árvores!/ Os longos anos se passaram como goles rápidos/ do doce hidromel em salões altos/ além do Oeste sob as abóbadas azuis de Varda/ onde as estrelas tremem/ na canção de sua voz, de santa e rainha. [...]"
} 
A laita te, laita te! Andave laituvalmet!

$[\ldots] "$

Os dados levantados nessa análise ilustram diferentes maneiras em que o codeswitching ocorre quando há línguas artificiais envolvidas. Além disso, eles sugerem que as classificações de Dabène e Moore (1995) e as motivações de Mozzillo de Moura (1997), previamente descritas para línguas naturais, também podem ser utilizadas em interações com línguas artificiais em contextos multilíngues.

\section{Considerações finais}

Diante do que foi exposto, percebe-se que as línguas artificiais têm sido objeto de interesse de filólogos, escritores e cientistas da linguagem. Inicialmente sob o intuito de estabelecer um método de comunicação universal, hoje elas também têm se inserido num escopo artístico, sendo então utilizadas como material de contemplação e de enriquecimento para narrativas literárias.

Assim, esses universos bilíngues artificiais também estão sujeitos à análise de perspectivas que tratem sobre o bilinguismo e as línguas em contato, em especial o codeswitching.

Por se tratar de um grande marco na carreira de Tolkien e na história da literatura do século XX, O Senhor dos Anéis reúne uma robusta riqueza narrativa digna de apreciação e de análise literária e linguística. Por essa razão, esse artigo é uma modesta homenagem que pretende se juntar a outros tantos trabalhos científicos e empíricos para valorizar o inesgotável legado tolkeniano.

A proposta de Mozzillo de Moura (1997) parece contemplar um vasto conjunto de motivações observadas em interações bilíngues e, por isso, serviu de base para as interpretações nesse artigo. Como foi observado nessa pesquisa, as situações de perigo ou ameaça e os rituais e cerimônias são contextos que favorecem o code-switching. A alternância é um recurso que traz ganhos não somente para os atos comunicativos entre as personagens, mas também ajuda a construir mais elementos dentro da narrativa. Mais 
análises desse tipo podem ser realizadas em obras de J. R. R. Tolkien ou George R. R. Martin, por exemplo, a fim de complementar o corpus de motivações que levam ao codeswitching ou de acrescentar outras que sejam específicas às suas narrativas.

\section{Referências}

DABÈNE, L; MOORE, D. Bilingual speech of migrant people. In: MILROY, L.; MUYSKEN, P. One speaker, two languages. Cross-disciplinary perspectives on codeswitching. Cambridge: Cambridge University Press, 1995.

FAUSKANGER, H.K. Curso de Quenya: A mais bela língua dos elfos. Curitiba: Arte \& Letra, 2011.

GREGGERSEN, G. O Senhor dos Anéis: da fantasia à ética. Viçosa: Ultimato, 2013. GROSJEAN, F. Individual Bilingualism. The Encyclopedia of Language and Linguistics. Oxford: Pergamon Press, 1994, pp. 1656-166o.

MOZZILLO DE MOURA, I. Motivações para a alternância de código no discurso bilíngue. Trabalhos de Linguística Aplicada, Campinas, Jan/Jun de 1997, pp. 51-67. MOZZILLO, I. O mito da pureza linguística confrontado pelo conceito de codeswitching. In: GT - Plurilinguismo e Contato Linguístico. Anais do CELSUL. 2008 . O code-switching: fenômeno inerente ao falante bilíngue. Papia, 2009, pp. 185200.

STÖRIG, J. H. A Aventura das Línguas. São Paulo: Companhia Melhoramentos, 1990. TOLKIEN, J.R.R. O Senhor dos Anéis: A Sociedade do Anel. São Paulo: Martins Fontes, 2000.

. O Senhor dos Anéis: As Duas Torres. São Paulo: Martins Fontes, 2000.

. O Senhor dos Anéis: O Retorno do Rei. São Paulo: Martins Fontes, 2000.

WHITE, M. J. R. R. Tolkien, o senhor da fantasia: edição comemorativa. Rio de Janeiro: DarkSide Books, 2016. 
ALMEIDA, Vinicius Borges de; MOZZILLO, Isabella

Recebido em 03/o6/2020.

Aprovado em o1/10/2020.

Revista Investigações, Recife, v. 33, n. 2, p. 1 - 16, 2020 ISSN Digital 2175-294x 